\title{
Influence of the appendicular skeletal muscle mass index on the bone mineral density of postmenopausal women
}

\author{
Geise Ferreira da Cruz ${ }^{1}$, Tatiana Mion Lunz ${ }^{2}$, Tatielle Rocha de Jesus ${ }^{2}$, Mariana Braga Costa², \\ Camila Vilarinho Vidigal ${ }^{2}$, Ben-Hur Albergaria ${ }^{3}$, Jose Luiz Marques-Rocha ${ }^{1,2}$ and Valdete Regina Guandalini ${ }^{1,2^{*}}$
}

\begin{abstract}
Background: The appendicular skeletal muscle mass index (ASMI) is an important risk indicator for osteoporosis because of the anatomical proximity and metabolic connection between muscle and bone mass. The present study investigated the relationship between ASMI and the bone mineral density (BMD) categories of postmenopausal women.

Methods: In this cross-sectional study with a probabilistic sample, sociodemographic, lifestyle, menopause time, anthropometric, and physical activity variables were collected. ASMI and BMD were assessed by dual-energy X-ray absorptiometry (DXA). Participants were grouped according to BMD values into normal density, osteopenia, and osteoporosis. Multivariate logistic regression models were applied to verify the influence of ASMI on BMD. Data were analyzed using the SPSS statistical software, version 22. The significance level for all tests was set at 5\%.
\end{abstract}

Results: Of the 114 women analyzed, most were between 60 and 69.9 years of age (62.3\%), on menopause for $\leq 19.0$ (51.8\%), self-declared brown race/color (49.1\%), had < 4years of education (41.2\%), never smoked (69.0\%) or drank alcohol (62.8\%). Of these, $52.6 \%$ were classified as sufficiently active and $52.2 \%$ had regular sun exposure. Women with osteoporosis were older $(p=0.035)$, on menopause for a longer time $(p=0.011)$, underweight $(p=0.004)$, had adequate waist circumference $(p=0.017)$, and low ASMI values $(p=0.002)$. There was an association between the 1 st tertile of ASMI and osteoporosis. However, after adjustments for age, race/color, and body mass index, the strength of association between BMD and ASMI was not maintained.

Conclusions: ASMI was not associated with the BMD of the postmenopausal women evaluated. Total body and muscle mass, in addition to bone mass, should be monitored during menopause treatment. Longitudinal studies must be conducted to elucidate the mechanisms and gaps in this relationship.

Keywords: Osteoporosis. Menopause. Body composition. Densitometry, Sarcopenia

\footnotetext{
*Correspondence: valdete.guandalini@ufes.br

${ }^{2}$ Department of Integrated Education, Federal University of Espirito

Santo, Marechal Campos, avenue, 1468 - Maruípe, Vitória, Espírito Santo CEP: 29040-090, Brazil

Full list of author information is available at the end of the article
}

\section{Background}

Skeletal muscle mass (SMM) performs mechanical, structural, and metabolic functions in the human body [1]. Muscle mass is constantly changing from birth until it reaches its maximum peak at around 30 years of age. In adulthood, several factors interfere in the development of SMM, such as genetics, race/color, diet, physical activity, and hormone levels [2]. original author(s) and the source, provide a link to the Creative Commons licence, and indicate if changes were made. The images or other third party material in this article are included in the article's Creative Commons licence, unless indicated otherwise in a credit line to the material. If material is not included in the article's Creative Commons licence and your intended use is not permitted by statutory regulation or exceeds the permitted use, you will need to obtain permission directly from the copyright holder. To view a copy of this licence, visit http://creativecommons.org/licenses/by/4.0/. The Creative Commons Public Domain Dedication waiver (http://creativeco mmons.org/publicdomain/zero/1.0/) applies to the data made available in this article, unless otherwise stated in a credit line to the data. 
With increasing age, the musculoskeletal system progressively declines $[3,4]$, with consequent reduction in functional capacity and possible development of diseases such as osteoporosis and sarcopenia $[3,5]$.

The term sarcopenia was first used in 1989 by Irwin Rosenberg to refer to age-related loss of muscle mass and strength [6]. Years later, Baumgartner et al. [7] proposed the use of appendicular skeletal muscle mass (ASM) adjusted by height squared, called the appendicular skeletal muscle mass index (ASMI), as an indicator of low muscle mass $[7,8]$. Since then, ASMI has been used as one of the main parameters to assess body muscle mass $[3,9]$.

In 2010, the European Working Group on Sarcopenia in Older People (EWGSOP) improved the concept of sarcopenia and recommended, in addition to low muscle mass, the use of low muscle strength or low physical performance for the diagnosis [10]. In its most recent review, the EWGSOP2 proposed an algorithm for the diagnosis of sarcopenia, followed by the assessment of muscle strength (pre-sarcopenia), low quantity or quality of muscle mass (sarcopenia), and impaired physical performance associated to the aforesaid parameters (severe sarcopenia) [3].

Although this aging-related musculoskeletal decline is common to all individuals $[3,6]$, it is accelerated in postmenopausal women, being mainly related to changes in the levels of hormones with important functions in bone and muscle health [11-14].

Regarding muscle mass, it has been suggested that low estrogen production, especially of the hormone estradiol, may favor sarcopenia [13, 14]. Through estrogen betareceptors present in skeletal muscle, estradiol stimulates the activation and proliferation of satellite cells, promoting muscle repair. Reduced estrogen levels compromise this maintenance [14], in addition to being associated with an increase in pro-inflammatory cytokines that can degrade muscle proteins and reduce muscle regeneration capacity $[11,14]$.

Another mechanism involves the decrease in the hormone dehydroepiandrosterone (DHEA), which is related to the reduction in physical performance and muscle mass in women after menopause [15]. The decrease in testosterone levels after the first years of menopause is concomitant with the decrease in muscle mass, in which it plays an important role [11].

Regarding bone mass, estrogen regulates the coupling between bone resorption and formation [13]. With the reduction in estrogen production caused by menopause, osteoblasts produce an excess of the cytokine RANKL, which promotes osteoclastogenesis and bone resorption when bound to the RANK receptor $[15,16]$. Estrogen deficiency reduces the secretion of osteoprotegerin
(OPG), an inhibitor of RANKL secreted by osteoblasts after estrogen stimulation, thus increasing the activity of this cytokine. As a result, there is an increase in resorption at the expense of bone formation, which leads to skeletal disorder and deterioration in bone mineral density (BMD) $[13,16]$.

Bone mineral density is assessed using dual energy $\mathrm{x}$-ray absorptiometry (DXA) and classified into normal BMD, osteopenia, osteoporosis, and osteoporosis associated with fracture risk, as established by the World Health Organization (WHO) [17].

Previous studies that evaluated the relationship between SMM and bone mass in postmenopausal women failed to clarify this relationship [7-14], producing conflicting results $[18,19]$. These divergences may be related to the characteristics of the population and study design, methods for measuring and classifying SMM, as well as factors such as menopause time and muscle mass index, which can exert greater influence on bone mass when compared to SMM $[15,16]$.

Although SMM incites a growing interest, many studies use lean mass (muscles, tendons, and connective tissue) or total lean soft tissue (skeletal muscle mass and that of all other organs) as synonyms for SMM, what can affect the analysis of the aforementioned relationship [20, 21]. To investigate the influence of SMM on the preservation - or lack thereof - of bone mass, ASMI must be determined from the SMM obtained through dualenergy X-ray absorptiometry (DXA) [22].

Few studies analyzed the relationship between ASMI and BMD in postmenopausal women [4, 20, 23-29]. Therefore, starting from the premise that aging, associated with post-menopause, affects SMM negatively and potentializes the reduction of bone mass, in the present study we investigated the relationship between ASMI and the BMD categories of postmenopausal women.

\section{Methods}

Cross-sectional observational study conducted on a probabilistic sample from the Climacteric and Osteoporosis Outpatient Clinics of a University Hospital in Vitória, Espírito Santo, Brazil, carried out from June 2019 to March 2020.

\section{Population}

The study population consisted of postmenopausal women seen at a secondary-level public service. The inclusion criteria considered for this study were women aged between 55 and 85 years, in menopause for at least 12 months. Those under hormone replacement therapy, with cardiac implants, and who did not answer four telephone contact attempts were excluded. 


\section{Sampling and sample drawing}

The sample size was based on the number of consultations that took place in 2018 at the aforementioned clinics, which corresponded to 527 consultations. Duplicate consultations and women under 50 years of age $(n=185)$ were excluded, with 342 women remaining eligible for the study. A $95 \%$ confidence interval, a $5 \%$ margin of error, and a $21.3 \%$ prevalence of osteoporosis in women over 50 years of age were considered [30], resulting in a sample of 147 women.

The sample was selected through a simple random drawing using Excel $^{\circledR}$ (Office 2016), allocated in a list, and drawn in a single step. Those who refused to participate in the study were replaced in a new drawing.

After this step, the women were invited to participate in the study via telephone contact.

\section{Instruments and study variables}

Data were collected by properly trained and qualified professionals on the premises of the ELSA Investigation Center in the Espírito Santo state (IC-ES). A semistructured questionnaire containing sociodemographic information (age in years, marital status, education and self-reported race/color). Self-declared race/color was defined as white, black, brown, yellow, and indigenous, as recommended by the Brazilian Institute of Geography and Statistics [31]. Lifestyle (smoking, alcohol consumption, level of physical activity, and sun exposure) and menopause time (years) were also evaluated. Women were classified as adult (<60years) and elderly $(\geq$ 60 years) according to the WHO classification for developing countries [32].

Body mass and height were measured according to the method recommended by Lohman et al. [33]. BMI was calculated as the ratio between body mass $(\mathrm{kg})$ and squared height $\left(\mathrm{m}^{2}\right)$ and classified according to the WHO for adults [34] and to the recommendations of the Pan American Health Organization (PAHO) for the elderly [35].

Calf circumference $(\mathrm{CC})$ was measured at the largest point of the calf, with the patient in the sitting position and knees flexed at 90 degrees [33]. Values $\leq 33 \mathrm{~cm}$ were classified as reduced [36]. Waist circumference (WC) was measured in duplicate at the midpoint between the last rib and the iliac crest. Values $\geq 80 \mathrm{~cm}$ were classified as high [34].

Handgrip strength (HGS) was assessed both in the dominant hand (DHGS) and in the non-dominant hand (NDHGS) through the method recommended by the American Society of Hand Therapists (ASHT) [37]. The process was conducted in triplicate with 1-min interval between measurements: maximum force was applied for
$5 \mathrm{~s}$ while the individual evaluated was verbally encouraged. The maximum value was considered for analysis. The cutoff point adopted was $<16.0 \mathrm{~kg}$, as proposed by the European Working Group on Sarcopenia in Older People (EWGSOP2) [3].

The Timed Get-Up-and-Go test (TUG) was performed according to the method proposed by Podsiadlo and Richardson [38]. The test was performed in triplicate using the mean time value and adopting a cutoff point of $>20 \mathrm{~s}$ [3].

To obtain ASMI, the appendicular skeletal muscle mass (ASM) was first estimated through Dual-Energy X-ray Absorptiometry (DXA) (GE Lunar Prodigy Advance ${ }^{\circledR}$ ), using the GE Encore software, version 14.10, properly calibrated and configured to use the reference database of the National Health and Nutrition Examination Survey [39]. For the examination, women fasted for $4 \mathrm{~h}$ beforehand, wore only a gown, and met the recommendations of the International Society for Clinical Densitometry [40]. To minimize interobserver variation, all body densitometry examinations were performed only by a properly trained, certified radiology technician and were interpreted and signed by a single physician. Subsequently, ASMI was calculated as the ratio between ASM $(\mathrm{kg})$ and squared height $\left(\mathrm{m}^{2}\right)$ [3]. Values were classified according to the tertiles themselves.

BMD was also identified by DXA and classified as normal BMD (T-score $\geq-1 \mathrm{DP}$ ), osteopenia (T-score between -1 and $-2.5 \mathrm{DP}$ ), and osteoporosis (T-score $\leq-2.5 \mathrm{DP}$ ), according to the cutoff points recommended by the WHO [17]. The proximal femur and lumbar spine (L1-L4) were evaluated for this diagnosis. Values were obtained from the medical record and confirmed with the physician in charge.

The level of physical activity (PA) was estimated using the International Physical Activity Questionnaire (IPAQ), validated for the Brazilian population in its long version [41]. To avoid the overestimation of PA levels, only the sum of questions related to leisure and transportation was considered [42]. Women who reported performing 150 min or more of weekly PA were classified as sufficiently active, while those deemed insufficiently active did not reach the level recommended by the WHO [43]. The participants were also asked about sun exposure habits and their answers dichotomized into yes or no.

\section{Ethical aspects}

The study complied with the Resolution CNS 466/12 of the Ministry of Health/Brazil [44] and was approved by the Research Ethics Committee of the Federal University of Espírito Santo under CAAE: 88131818.0.0000.5060 and protocol \#: 2.621.794. 


\section{Statistical analysis}

Descriptive analysis was expressed as percentage for categorical variables. For data analysis, the overweight and obese categories were categorized as overweight. Fisher's exact and chi-square tests were applied to verify the difference between proportions according to the BMD categories. Multivariate logistic regression models were adjusted considering two main outcomes: osteopenia and osteoporosis. All variables that presented $p$ values $<0.10$ in the bivariate associations were included in the models. Collinear or strongly correlated variables were not included in the models. Those with values of $p<0.05$ in the univariate analysis were kept in the final model. Odds ratio and the respective confidence intervals were calculated. Data were analyzed using the software SPSS 22.0 and the significance level adopted for all tests set at $5.0 \%$.

\section{Results}

In the final stage of sample selection, 44 women did not meet the inclusion criteria and, therefore, other women were drawn and included in the sample. After the final selection, 140 women were analyzed. However, the collection was interrupted due to the advance of the pandemic by the new coronavirus (SARS-CoV2), mainly because the study included a population at risk, thus our final sample included 114 women (Fig. 1).

Sociodemographic, lifestyle, and BMD variables are described in Table 1 . There was a predominance of women aged between 60 and 69.9years (62.3\%), on menopause for $\leq 19.0$ years (51.8\%), self-declared brown race/color (49.1\%), with less than four years of education $(41.2 \%)$, and who had never smoked $(69.0 \%)$ or consumed alcohol (62.8\%). Of these, $52.6 \%$ were classified as sufficiently active and $52.2 \%$ had regular sun exposure (Table 1).

BMD categories were significantly different in different age groups and menopause times $(p<0.05)$ (Table 1$)$. Osteoporosis was more prevalent among women aged $\geq 70.0$ years $(p=0.035)$ and those on menopause for over 19 years $(p=0.011)$.

When evaluating the distribution of anthropometric, body composition, HGS, and TUG variables within the BMD categories, we observed that osteoporosis was significantly more frequent in women with ASMI classified in the lowest tertile $(p=0.002)$, underweight $(p=0.004)$, and adequate WC $(p=0.017)$ (Table 2).

Figure 2 shows a significant difference between ASMI mean values according to the BMD categories. The average ASMI of the normal BMD group was $7.78 \mathrm{~m}^{2}$, while in the osteopenia and osteoporosis groups it was $6.72 \mathrm{~m}^{2}$ and $5.68 \mathrm{~m}^{2}$, respectively. Differences were observed between the osteoporosis group and the normal BMD and osteopenia groups $(p=0.001)$.

After adjustments for age group and race/color (model 1), we observed that the 1st tertile of the ASMI remained associated with osteoporosis (OR: 10.45 [CI 95\%: 1.7462.7]). However, after adjusting for age group, race/color, and BMI (model 2), the strength of association between ASMI and BMD was not maintained (Table 3).

\section{Discussion}

In this study, ASMI did not remain associated with the BMD of postmenopausal women after the proposed adjustments. The women evaluated showed satisfactory lifestyle habits: they did not smoke or take alcohol, were physically active, and had preserved muscle mass and functional capacity, albeit associated with a

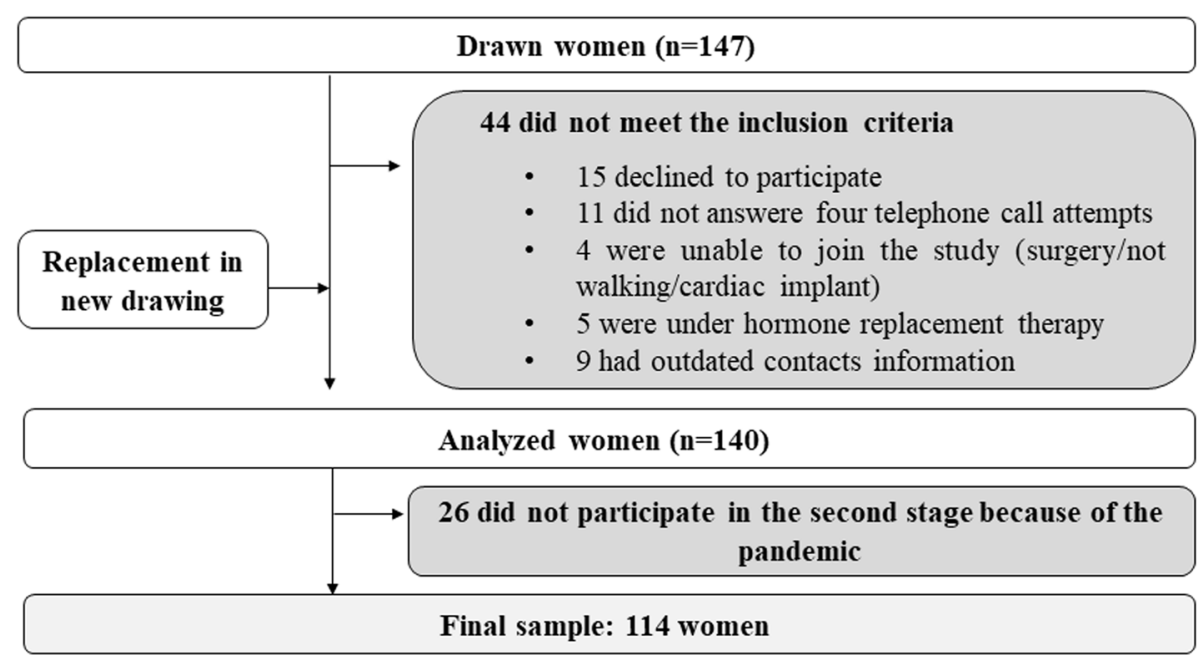

Fig. 1 Selection Flowchart 
Table 1 Distribution of sociodemographic and lifestyle variables according to bone mineral density (BMD) of postmenopausal women

\begin{tabular}{|c|c|c|c|c|c|}
\hline \multirow[t]{2}{*}{ Variables } & \multirow[t]{2}{*}{ Total } & \multicolumn{3}{|l|}{ BMD } & \multirow[t]{2}{*}{$\mathrm{p}$ value } \\
\hline & & $\begin{array}{l}\text { Normal } \\
(n=27 ; \\
23.7 \%)\end{array}$ & $\begin{array}{l}\text { Osteopenia } \\
(n=48 ; \\
42.1 \%)\end{array}$ & $\begin{array}{l}\text { Osteoporosis } \\
(n=39 ; \\
34.2 \%)\end{array}$ & \\
\hline Age group (years) ${ }^{a}$ & & & & & 0.035 \\
\hline $50.0-59.9$ & $15(13.2)$ & $7(46.7)$ & $7(46.7)$ & $1(6.7)$ & \\
\hline $60.0-69.9$ & $71(62.3)$ & $17(23.9)$ & $28(39.4)$ & $26(36.6)$ & \\
\hline$\geq 70.0$ & $28(24.6)$ & $3(10.7)$ & $13(46.4)$ & $12(42.9)$ & \\
\hline Menopause time (years) ${ }^{b}$ & & & & & 0.011 \\
\hline$\leq 19.0$ & $59(51.8)$ & $20(33.9)$ & $25(42.4)$ & $14(23.7)$ & \\
\hline$>19.0$ & $55(48.2)$ & $7(12.7)$ & $23(41.8)$ & $25(45.5)$ & \\
\hline Race/color ${ }^{\text {b }}$ & & & & & 0.087 \\
\hline White & $43(37.7)$ & $10(46.5)$ & $13(30.2)$ & $20(46.5)$ & \\
\hline Black & $9(7.9)$ & $2(22.2)$ & $4(44.4)$ & $3(33.3)$ & \\
\hline Yellow & $6(5.3)$ & $2(33.3)$ & $2(33.3)$ & $2(33.3)$ & \\
\hline Brown & $56(49.1)$ & $13(23.2)$ & $29(51.8)$ & $14(25.0)$ & \\
\hline Schooling (years) ${ }^{b}$ & & & & & 0.331 \\
\hline$<4$ & $47(41.2)$ & $9(19.1)$ & $21(44.7)$ & $17(36.2)$ & \\
\hline $4-8$ & $32(28.1)$ & $10(31.3)$ & $9(28.1)$ & $13(40.6)$ & \\
\hline$>8$ & $35(30.7)$ & $8(22.9)$ & $18(51.4)$ & $9(25.7)$ & \\
\hline Smoking ${ }^{* a}$ & & & & & 0.937 \\
\hline Never smoked & $78(69.0)$ & $18(23.1)$ & $33(42.3)$ & $27(34.6)$ & \\
\hline Smokes & $6(5.3)$ & $1(16.7)$ & $2(33.3)$ & $3(50.0)$ & \\
\hline Used to smoke & $29(25.7)$ & $8(27.6)$ & $12(41.4)$ & $9(31.0)$ & \\
\hline Alcohol intake ${ }^{* a}$ & & & & & 0.549 \\
\hline Never drank & $71(62.8)$ & $18(25.4)$ & $27(38.0)$ & $26(36.6)$ & \\
\hline Drinks & $15(13.3)$ & $4(26.7)$ & $7(46.7)$ & $4(26.7)$ & \\
\hline Used to drink & $27(23.9)$ & $5(18.5)$ & $13(48.1)$ & $9(33.3)$ & \\
\hline Physical activity level ${ }^{* b}$ & & & & & 0.380 \\
\hline Insufficiently active & $53(46.5)$ & $15(28.3)$ & $23(43.4)$ & $15(28.3)$ & \\
\hline Sufficiently active & $60(52.6)$ & $12(20.0)$ & $24(40.0)$ & $24(40.0)$ & \\
\hline Sun exposure ${ }^{* * b}$ & & & & & 0.451 \\
\hline Yes & $58(52.2)$ & $14(24.1)$ & $21(36.2)$ & $23(39.7)$ & \\
\hline No & $53(47.8)$ & $12(22.6)$ & $25(47.2)$ & $16(30.2)$ & \\
\hline
\end{tabular}

${ }^{*} n=113 ;{ }^{* *} n=111 ;$ BMD: bone mineral density; ${ }^{\text {a }}$ Fisher's exact test; ${ }^{\text {b }}$ Chi-square test. Bold: $p$ value $<0.05$

predominance of excess weight and central adiposity. These lifestyle and nutritional status characteristics may have influenced the results obtained, as they act directly in the preservation of bone and muscle mass [15, 45-48].

The relationship between ASMI or SMM and BMD, although widely discussed, is still uncertain [49]. The results of this study differ from data available in the literature that suggest SMM influences bone mass proportionally. Some studies state that this association reflect not only the effect of mechanical muscle load on bone tissue, through muscle contraction, but also the functional relationship between these two systems [4, 25, 29].
On the other hand, other investigations found no association between ASMI and BMD, corroborating our results [24, 27, 50-53].

Some hypotheses suggest that factors such as excess weight and central adiposity may influence BMD through different mechanisms, such as adaptation of the bone structure to support the body's adipose tissue mass [54]. Another mechanism would be the increase in the aromatization of androgens into estrogen in the adipose tissue, thus stimulating bone formation in women after menopause $[51,55]$.

These inconclusive results are in great part attributed to the use of different methods to measure muscle 
Table 2 Distribution of anthropometric, body composition, handgrip strength, and Timed Get Up and Go test variables according to bone mineral density (BMD) categories in postmenopausal women

\begin{tabular}{|c|c|c|c|c|c|}
\hline \multirow[t]{2}{*}{ Variables } & \multirow[t]{2}{*}{ Total } & \multicolumn{3}{|l|}{ BMD } & \multirow[t]{2}{*}{$p$ value } \\
\hline & & $\begin{array}{l}\text { Normal } \\
(n=27 \\
23.7 \%)\end{array}$ & $\begin{array}{l}\text { Osteopenia } \\
(n=48 \\
42.1 \%)\end{array}$ & $\begin{array}{l}\text { Osteoporosis } \\
(n=39 \\
34.2 \%)\end{array}$ & \\
\hline $\operatorname{ASMI}\left(\mathrm{m}^{2}\right)^{\mathrm{a}}$ & n (\%) & & & & 0.002 \\
\hline $\begin{array}{c}1 \text { st tertile } \\
(5.68 \pm 0.31)\end{array}$ & $38(33.3)$ & $2(5.3)$ & $16(42.1)$ & $20(52.6)$ & \\
\hline $\begin{array}{c}\text { 2nd tertile } \\
(6.72 \pm 0.28)\end{array}$ & 38 (33.3) & $14(36.8)$ & 12 (31.6) & $12(31.6)$ & \\
\hline $\begin{array}{r}\text { 3rd tertile } \\
(7.78 \pm 0.53)\end{array}$ & 38 (33.3) & $11(28.9)$ & $20(52.6)$ & $7(18.4)$ & \\
\hline $\mathrm{BMI}^{\mathrm{b}}$ & & & & & 0.004 \\
\hline $\begin{array}{l}\text { Under- } \\
\text { weight }\end{array}$ & $20(16.7)$ & $1(5.0)$ & $7(35.0)$ & $12(60.0)$ & \\
\hline Eutrophic & 43 (38.6) & $9(20.9)$ & $16(37.2)$ & $18(41.9)$ & \\
\hline $\begin{array}{l}\text { Over- } \\
\text { weight }\end{array}$ & $51(44.7)$ & $17(33.3)$ & $25(49.0)$ & $9(17.6)$ & \\
\hline $\mathrm{CC}^{\mathrm{b}}$ & & & & & 0.186 \\
\hline Adequate & $98(86.0)$ & $26(26.5)$ & 39 (39.8) & $33(33.7)$ & \\
\hline Reduced & $16(14.0)$ & $1(6.3)$ & $9(56.3)$ & $6(37.5)$ & \\
\hline$w c^{b}$ & & & & & 0.017 \\
\hline Adequate & $13(11.4)$ & $1(7.7)$ & $3(23.1)$ & $9(69.2)$ & \\
\hline Elevated & 101 (88.6) & $26(25.7)$ & $45(44.6)$ & $30(29.7)$ & \\
\hline DHGS $^{b}$ & & & & & 0.250 \\
\hline Adequate & 107 (93.9) & $25(23.4)$ & 47 (43.9) & $35(32.7)$ & \\
\hline Reduced & $7(6.1)$ & $2(28.6)$ & $1(14.3)$ & $4(57.1)$ & \\
\hline $\mathrm{NDHGS}^{\mathrm{b}}$ & & & & & 0.546 \\
\hline Adequate & $100(87.7)$ & $23(23.0)$ & $44(44.0)$ & $33(33.0)$ & \\
\hline Reduced & $14(12.3)$ & $4(28.6)$ & 4 (28.6) & $6(42.9)$ & \\
\hline TUG $(s)^{b}$ & & & & & 1.000 \\
\hline Adequate & 111 (97.4) & $26(23.4)$ & $47(42.3)$ & $38(34.2)$ & \\
\hline Inadequate & $3(2.6)$ & $1(33.3)$ & $1(33.3)$ & $1(33.3)$ & \\
\hline
\end{tabular}

ASMI Appendicular Skeletal Muscle Mass Index, BMI Body Mass Index, CC Calf Circumference, $m$ WC Waist circumference, $H C$ Hip Circumference, DHGS Dominant handgrip strength, NDHGS Non-Dominant Handgrip Strength, TUG Timed Get Up and Go test. ${ }^{a}$ Chi-square test; ${ }^{b}$ Fisher's exact test. Bold: $p$ value $<0.05$

mass, added to the heterogeneity of the DXA-measured ASMI nomenclature or even the lack of consensus in the literature to define ASMI and its cutoff points, making it difficult to compare and discuss the results $[21,51,56,57]$.

Due to the lack of Brazilian references, the EGWSOP2 proposal was used to define ASMI [3] which has been considered the most recommended to define muscle mass depletion [22], in addition to demonstrating greater associations with negative clinical outcomes $[3,23,57$, 58]. Furthermore, lean mass, which is composed of bone, skin, and muscle, is misused as SMM, what can result in confusing conclusions about the influence of SMM on
BMD [21]. Finally, the individuals total body mass and body composition may also influence the bone-muscle relationship [19, 27].

According to Saarelainen et al. [51], who evaluated 198 Finnish postmenopausal women, excess weight and fat distribution affect the measurement of muscle mass by overestimating BMD, making it important to control these components. This fact may explain the results obtained here, since the women evaluated were overweight and had abdominal fat accumulation. This explanation can also be supported by the fact that after adjustment for BMI in the final regression models, the association between ASMI and BMD was lost. In this group, BMI seems to have influenced BMD more than ASMI, much like previously reported outcomes $[59,60]$.

As to the possibility that bone mass increases or decreases linearly based on BMI values [51], here we observed that the higher prevalence of osteoporosis was associated with low weight according to BMI, thus confirming this possibility. Low weight is considered a risk factor for the development of osteoporosis [19, $46,61]$. A population-based meta-analysis that evaluated BMI as a predictor of fracture risk showed that low weight confers a marked risk for all osteoporotic fractures, regardless of age and sex, but dependent on BMD [61].

Mazocco and Chagas [59], when evaluating 393 Brazilian postmenopausal women, identified a lower prevalence of osteopenia and osteoporosis among obese women. Likewise, Shayganfar et al. [19] observed a significant increase in BMD with an increase in BMI in 1056 postmenopausal women. However, although some studies support the beneficial effect of excess weight on BMD, it is important to emphasize that obesity is a risk factor for different comorbidities [62]. Both low weight and obesity can determine the intensification of osteoporosis and adversely affect the function and quality of SMM in postmenopausal women, in addition to their general health and quality of life [55, $60,62,63] .$.

The investigation and clarification that between of the influence that SMM plays on bone mass in postmenopausal women is a challenge, given the many variables that can affect these tissues and need to be controlled and included in future studies, such as serum hormonal levels and the use of protein supplementation.

This study has as a limitation not being representative of the general population of postmenopausal women, as it was carried out with a single group of women seen at a secondary level outpatient clinic of a public health service, thus preventing extrapolation of the results. On the other hand, as a contribution, this study is one of the few 


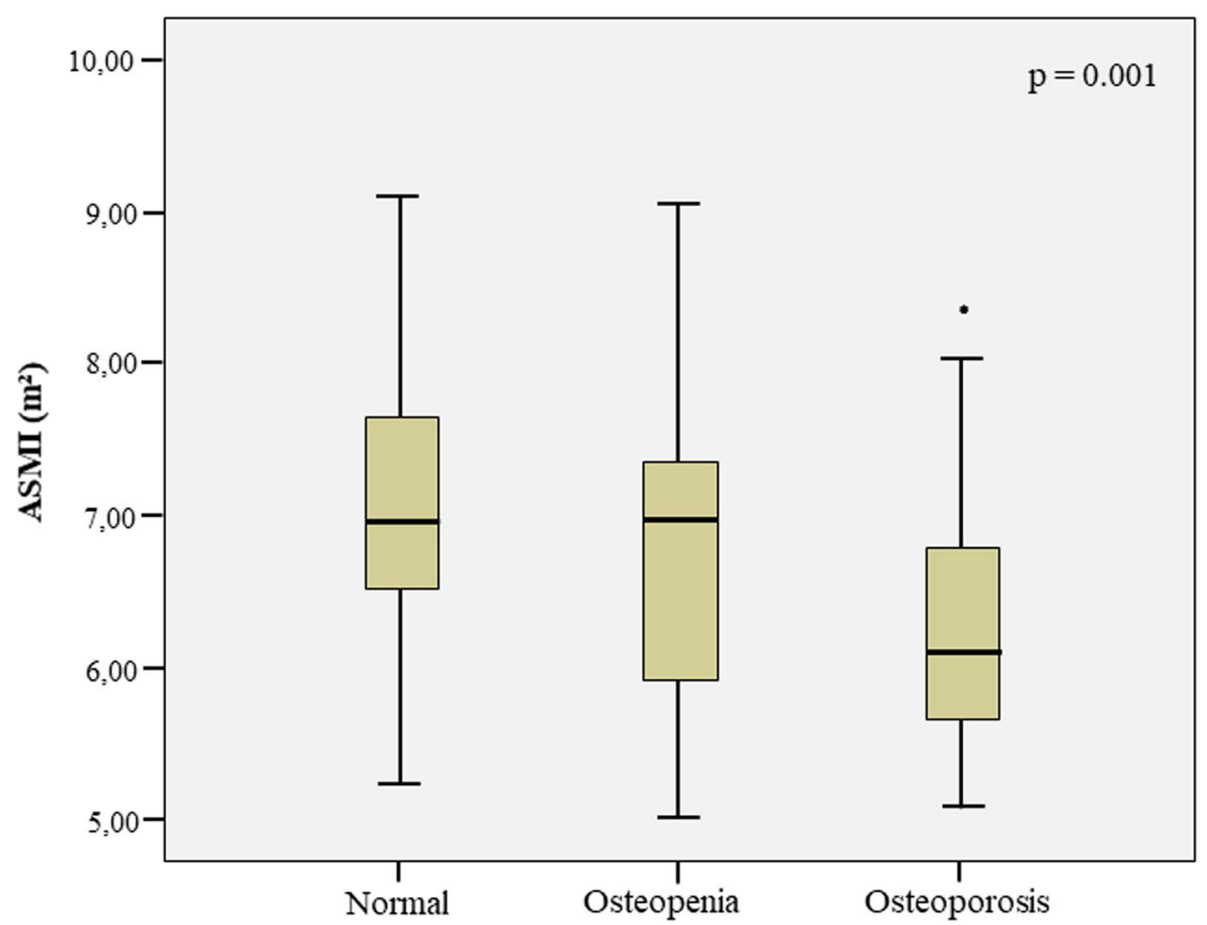

Fig. 2 Boxplot of the Appendicular Skeletal Muscle Mass Index (ASMI) according to bone mineral density (BMD) categories. *Difference observed between women with normal BMD and osteoporosis

Table 3 Logistic regression models for the appendicular skeletal muscle mass index (ASMI) according to bone mineral density (BMD) in postmenopausal women

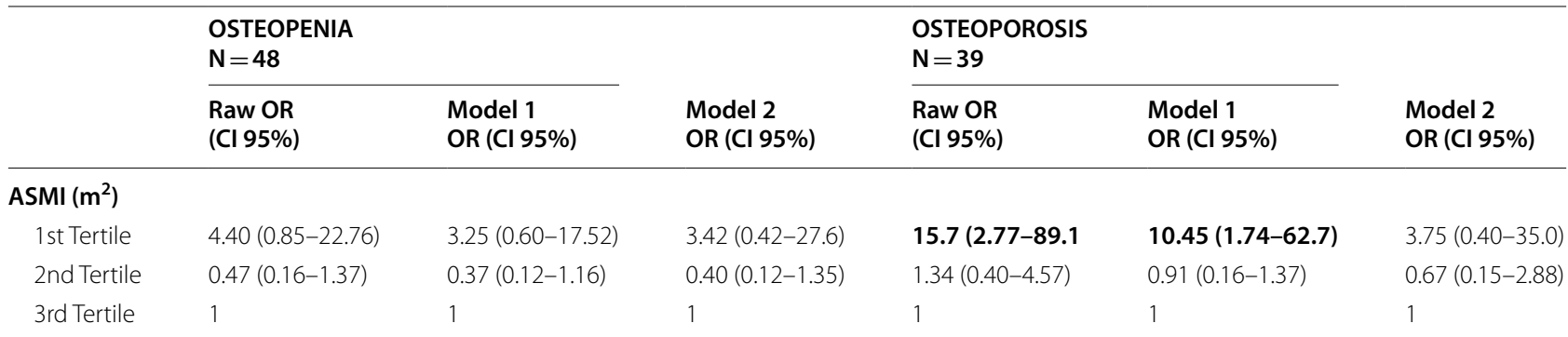

OR Odds Ratio. Model 1: adjusted for age group and race/color. Model 2: adjusted for age group, race/color, and body mass index. Bold: $p$ value < 0.05 . Normal BMD: reference

investigating the influence of ASMI on the BMD of postmenopausal women in outpatient care, using a reference standard for the analysis of muscle mass and BMD, in addition to validated questionnaires. In practical terms, the reported outcomes are clinically valid. We believe longitudinal studies should be conducted to elucidate the mechanisms and gaps in the relationship between ASMI and BMD.
The results of this study demonstrate the importance of monitoring body mass during menopause treatment, prioritizing the preservation of muscle mass and reduction of bone mass depletion. Therefore, the adoption of healthy lifestyle habits should be encouraged, including the practice of physical activity and dietary intervention, such as an adequate protein intake or supplementation when necessary. 


\section{Conclusion}

ASMI was not associated with BMD in the postmenopausal women evaluated. Among women with osteoporosis, there was a higher prevalence of those aged over 70 years, on menopause for a longer time, and with adequate $\mathrm{WC}$, in addition to women with lower ASMI averages and classified as underweight. This study demonstrates the importance of tracking total body and muscle mass, as well as bone mass during menopause treatment.

\begin{abstract}
Abbreviations
ASMI: Appendicular Skeletal Muscle Mass Index; BMD: Bone Mineral Density; SMM: Skeletal Muscle Mass; BMI: Body Mass Index; CC: Calf circumference; WC: Waist circumference; HC: Perímetro do Quadril. Hip circumference; DHGS: Dominant Handgrip Strength; NDHGS: Non-dominant Handgrip Strength; TUG: Timed Get-Up-and-Go test; OR: Odds Ratio; PA: Physical Activity; WHO: World Health Organization; PAHO: Pan American Health Organization; ASHT: American Society of Hand Therapists; IPAQ: International Physical Activity Questionnaire; DXA: Dual Energy X-ray Absorptiometry; Cl- ES: ELSA Investigation Center in the Espírito Santo state.
\end{abstract}

\section{Acknowledgements}

We would like to thank the Cassiano de Moraes University Hospital, especially Dr. José Geraldo Mill, for the support. We are also grateful for the scholarship granted by the Coordination for the Improvement of Higher Education Personnel - Brazil (CAPES). The authors also thank our study participants for their permission.

\section{Authors' contributions}

GFC, JLMR and VRG: concept and design research; GFC, TML, TRJ, MBC, BA and CVV: conducted research; GFC and VRG: analyzed data; GFC, JLMR and VRG: wrote paper; GFC, JLMR and VRG: had primary responsibility for final content. The authors read and approved the final manuscript.

\section{Funding}

The Coordenação de Aperfeiçoamento de Pessoal de Nível Superior - Brasil (CAPES) - Finance Code 001 awarded the scholarship to the principal researcher.

\section{Availability of data and materials}

The data that support the findings of this study are available from the corresponding author on reasonable request.

\section{Declarations}

\section{Ethics approval and consent to participate}

The study was conducted in accordance with the Resolution 466 of December 08, 2012, of the National Health Council of Brazil. Ethical approval for this study was obtained from the Research Ethics Committee of the Federal University of Espírito Santo - Parecer $n^{\circ}$ 2.621.794. Patients participated voluntarily and provided written informed consent.

\section{Consent for publication}

Not applicable.

\section{Competing interests}

The authors declare that they have no conflict of interest.

\section{Author details}

${ }^{1}$ Postgraduate Program in Nutrition and Health, Federal University of Espirito Santo, Marechal Campos, avenue, 1468 - Maruípe, Vitória, Espírito Santo CEP: 29040-090, Brazil. ²Department of Integrated Education, Federal University of Espirito Santo, Marechal Campos, avenue, 1468 - Maruípe, Vitória, Espírito Santo CEP: 29040-090, Brazil. ${ }^{3}$ Department of Social Medicine, Federal University of Espirito Santo, Marechal Campos avenue, 1468 - Maruípe, Vitória, Espírito Santo CEP: 29040-090, Brazil.
Received: 23 July 2021 Accepted: 28 September 2021

Published online: 09 October 2021

\section{References}

1. Duda K, Majerczak J, Nieckarz Z, Heymsfield SB, Zoladz JA, Duda K, et al. Human body composition and muscle mass. In: Muscle and Exercise Physiology: Elsevier; 2019. p. 3-26.

2. Tortora GJ, Derrickson B. Corpo Humano: Fundamentos de Anatomia e Fisiologia. Artmed Editora; 2016.

3. Cruz-Jentoft A, Bahat G, Bauer J, Boirie Y, Bruyère $O$, Cederholm T, et al. Sarcopenia: revised European consensus on definition and diagnosis. Age Ageing. 2019;48(1):16-31.

4. Jang SY, Park J, Ryu SY, Choi SW. Low muscle mass is associated with osteoporosis: a nationwide population-based study. Maturitas. 2020;133:54-9. https://doi.org/10.1016/j.maturitas.2020.01.003.

5. Iolascon G, Moretti A, de Sire A, Liguori S, Toro G, Gimigliano F. Pharmacological therapy of sarcopenia: past, present and future. Clin Cases Miner Bone Metab. 2018;15(3):407-15.

6. Rosenberg IH. Summary comments. Am Soc Clin Nutr. 1989;50:1231-3.

7. Baumgartner RN, Koehler KM, Gallagher D, Romero L, Heymsfield SB, Ross RR, et al. Epidemiology of sarcopenia among the elderly in New Mexico. Am J Epidemiol. 1998 Apr 15;147(8):755-63. https://doi.org/10.1093/oxfor djournals.aje.a009520.

8. Janssen I, Heymsfield SB, Wang ZM, Ross R. Skeletal muscle mass and distribution in 468 men and women aged 18-88 yr. J Appl Physiol. 2000;89(1):81-8. https://doi.org/10.1152/jappl.2000.89.1.81.

9. Albano D, Messina C, Vitale J, Sconfienza LM, Dennison E, Al-Daghri NM, et al. Imaging of sarcopenia: old evidence and new insights. Eur Radiol. 2019:30(4):2199-208.

10. Cruz-Jentoft AJ, Baeyens JP, Bauer JM, Boirie Y, Cederholm T, Landi F, et al. Sarcopenia: European consensus on definition and diagnosis. Age Ageing. 2010;39(4):412-23.

11. Messier V, Rabasa-Lhoret R, Barbat-Artigas $S$, Elisha B, Karelis AD, AubertinLeheudre M. Menopause and sarcopenia: a potential role for sex hormones. Maturitas. 2011;68(4):331-6. https://doi.org/10.1016/j.maturitas. 2011.01.014

12. Karvonen-Gutierrez C, Kim C. Association of mid-Life Changes in body size, body composition and obesity status with the menopausal transition. Healthcare. 2016:4(3):42.

13. Davis SR, Lambrinoudaki I, Lumsden M, Mishra GD, Pal L, Rees M, et al. Menopause. Nat Rev Dis Prim. 2015;1:1-19.

14. Geraci A, Calvani R, Ferri E, Marzetti E, Arosio B, Cesari M. Sarcopenia and menopause: the role of estradiol. Front Endocrinol. 2021;12(May):1-5.

15. Tey SL, Chew STH, How CH, Yalawar M, Baggs G, Chow WL, et al. Factors associated with muscle mass in community-dwelling older people in Singapore: findings from the SHIELD study. PLoS One. 2019;14(10):1-20.

16. Alejandro P, Constantinescu F. A review of osteoporosis in the older adult: an update. Rheum Dis Clin N Am. 2018:44(3):437-51.

17. WHO. Who Scientific Group on the Assessment of Osteoporosis At Primary Health Care Level. World Health Summary Meeting Report Brussels. Belgium; 2004. p. 1-17, 2007. https://doi.org/10.1016/S0140-6736(02) 08761-5. Available in: http://www.who.int/chp/topics/Osteoporosis.pdf. Accessed 15 July 2021.

18. He H, Liu Y, Tian Q, Papasian C, HuT, Deng HW. Relationship of sarcopenia and body composition with osteoporosis. Osteoporos Int. 2015;27(2):473-82.

19. Shayganfar A, Ebrahimian S, Masjedi M, Daryaei S. A study on bone mass density using dual energy $X$-ray absorptiometry: Does high body mass index have protective effect on bone density in obese patients? J Res Med Sci. 2020;25(1). https://doi.org/10.4103/jrms.JRMS_1066_18.

20. Marin-Mio RV, Moreira LDF, Camargo M, Périgo NAS, Cerondoglo MS, Lazaretti-Castro $\mathrm{M}$, et al. Lean mass as a determinant of bone mineral density of proximal femur in postmenopausal women. Arch Endocrinol Metab. 2018;62(4):431-7.

21. Santana F, Domiciano D, Gonçalves M, Machado L, Figueiredo C, Lopes J, et al. Association of Appendicular Lean Mass, and subcutaneous and visceral adipose tissue with mortality in older Brazilians: the São Paulo Ageing \& Health Study. J Bone Miner Res. 2019 Jul 28;34(7):1264-74. https://doi.org/10.1002/jbmr.3710. 
22. Buckinx F, Landi F, Cesari M, Fielding RA, Visser M, Engelke K, et al. Pitfalls in the measurement of muscle mass: a need for a reference standard. J Cachexia Sarcopenia Muscle. 2018;9(2):269-78.

23. Papageorgiou M, Sathyapalan T, Schutte R. Muscle mass measures and incident osteoporosis in a large cohort of postmenopausal women. J Cachexia Sarcopenia Muscle. 2018;10(1):131-9.

24. Kapuš O, Gába A, Lehnert M. Relationships between bone mineral density, body composition, and isokinetic strength in postmenopausal women. Bone Rep. 2020;12. https://doi.org/10.1016/j.bonr.2020.100255.

25. Orsatti FL, et al. Low appendicular muscle mass is correlated with femoral neck bone mineral density loss in postmenopausal women.BMC Musculoskelet Disord. 2011;12:225. https://doi.org/10.1186/1471-2474-12-225.

26. Ilesanmi-Oyelere BL, Coad J, Roy N, Kruger MC. Lean Body Mass in the Prediction of Bone Mineral Density in Postmenopausal Women. Biores Open. 2018;7(1):150-8. https://doi.org/10.1089/biores.2018.0025.

27. El Hage R, Jacob C, Moussa E, Baddoura R. Relative importance of lean mass and fat mass on bone mineral density in a Group of Lebanese Postmenopausal Women. J Clin Densitom. 2011;14(3):326-31. https://doi. org/10.1016/j.jocd.2011.04.002.

28. Gillette-Guyonnet S, Nourhashemi F, Lauque S, Grandjean H, Vellas B. Body composition and osteoporosis in elderly women. Gerontology. 2000;46(4):189-93 www.karger.comwww.karger.com/journals/ger.

29. Zhu K, Hunter M, James A, Lim EM, Walsh JP, Zhu K, et al. Associations between body mass index, lean and fat body mass and bone mineral density in middle-aged Australians: the Busselton healthy ageing study. Bone. 2015;74:146-52. https://doi.org/10.1016/j.bone.2015.01.015.

30. Baccaro LF, MDSSV, Costa-Paiva L, Sousa MH, Osis MJ, Pinto-Neto AM, et al. Factors associated with osteoporosis in Brazilian women: a population-based household survey. Arch Osteoporos. 2013;8(1-2):1-9.

31. IBGE. Características étnico-raciais da população: Classificações e identidades. Estudos e Análises - Informação Demográfica e socioeconômica 2. Rio de Janeiro; 2013. p. 208.

32. WHO. World Health Organization. Health Topics: Ageing and Life Course. 2017. Available in: https://www.who.int/health-topics/ageing\#tab= tab_1. Accessed 23 Apr 2021.

33. Lohman TJ, Roache AF, Martorell R. Anthropometric standardization reference manual. Med Sci Sport Exerc. 1992;24(8):952.

34. WHO. World Health Organization technical report series. Physical status: the use and interpretation of anthropometry. Report of a WHO Expert Committee. 1995. p. 463. https://doi.org/10.1002/(sici)1520-6300(1996)8: 6<786::aid-ajhb11>3.0.co;2-i.

35. OPAS/SABE. Organización PanAmericana de La Salud. XXXVI Reunión Del Comité Asesor De Investigaciones En Salud - Encuesta Multicéntrica Salud Beinestar y Envejecimiento (SABE) em América Latina y el Caribe. Infome preliminar. 2001. p. 93.

36. Pagotto VI, Ferreira dos Santos KI, Gomes Malaquias SI, Márcia Bachion MI, Aparecida Silveira El, Pagotto VI, et al. Circunferência da panturrilha: validação clínica para avaliação de massa muscular em idosos. Rev Bras Enferm. 2018;71(2):343-50.

37. MacDermind J, Solomon G, Valdes K. Clinical Assessment Recommendations. Am Socity Surg Hand Ther. 2015;3rd(1):80.

38. Podsiadlo D, Richardson S. The timed up and go: a test of basic functional mobility for frail elderly persons. J Am Geriatr Soc. 1991;39(2):142-8.

39. NHANES. National Health and Nutrition Examination Survey. Body Composition Procedures Manual. 2018. p. 1-173, 2018. Available in: https:// wwwn.cdc.gov/nchs/data/nhanes/2017-2018/manuals/Body_Compo sition_Procedures_Manual_2018.pdf. Accessed 14 July 2021.

40. ISCD. International Society for clinical densitometry. Official Positions Adult ISCD 2019. 2019. p. 1-35. https://doi.org/10.1017/CBO9781107 415324.004. Available in: https://iscd.app.box.com/s/5r713cfzvf4gr28 q7zdccg2i7169fv86. Accessed 14 July 2021.

41. Matsudo S, Araújo T, Matsudo V, Andrade D, Andrade E, Oliveira LC, et al. Questionário Internacional de Atividade Física (Ipaq): Estudo de Validade e Reprodutibilidade no Brasil. Rev Bras Atividade Física e Saúde. 2001;6(2):5-18.

42. Hallal P, Gomez L, Parra D, Lobelo F, Mosquera J, Florindo A, et al. Lições Aprendidas Depois de 10 Anos de Uso do IPAQ no Brasil e Colômbia. J Phys Act Health. 2010;7(Suppl 2):259-64.

43. WHO. WHO Guidelines on physical activity and sedentary behaviour: World Health Organization; 2020. p. 104.

44. BRASIL. Ministério da Saúde. Conselho Nacional de Saúde. Resolução nº 466 de 12 de dezembro de 2012. Diretrizes e Normas Regulamentadoras de Pesquisa Envolvendo Seres Humanos. DOU n 12. Brasília; 2013. Seção 1 - Página 59. Available in: https://bvsms.saude.gov.br/bvs/saudelegis/ cns/2013/res0466_12_12_2012.html. Accessed 14 July 2021.

45. FEBRASGO. Federação Brasileira das Associações de Ginecologia e Obstetrícia. Manual Brasileiro de Osteoporose: orientações práticas para os profissionais de saúde. 1 ed. - São Paulo: Editora Clanad; 2021. p. 147. Available in: https://www.febrasgo.org.br/pt/component/k2/item/1298manual-brasileiro-de-osteoporose?highlight=WyJvc3Rlb3Bvcm9zZSJd. Accessed 30 July 2021.

46. IOF. Risk factors | International Osteoporosis Foundation: IOF; 2020.

47. Yang $L$, Wu GH, Yang YL, Wu YH, Zhang L, Wang MH, et al. Nutrition, physical exercise, and the prevalence of sarcopenia in elderly residents in nursing homes in China. Med Sci Monit. 2019;25:4390-9.

48. Seino S, Shinkai S, lijima K, Obuchi S, Fujiwara Y, Yoshida H, et al. Reference values and age differences in body composition of community-dwelling older Japanese men and women: a pooled analysis of four cohort studies. PLoS One. 2015;10(7):1-15.

49. Ho-Pham LT, Nguyen UDT, Nguyen TV. Association between lean mass, fat mass, and bone mineral density: a meta-analysis. J Clin Endocrinol Metab. 2014;99(1):30-8

50. Walsh MC, Hunter GR, Livingstone MB. Sarcopenia in premenopausal and postmenopausal women with osteopenia, osteoporosis and normal bone mineral density. Osteoporos Int. 2006 Jan;17(1):61-7.

51. Saarelainen J, Honkanen R, Kröger H, Tuppurainen M, Jurvelin JS, Niskanen $L$, et al. Body fat distribution is associated with lumbar spine bone density independently of body weight in postmenopausal women. Maturitas. 2011;69(1):86-90 https://doi.org/10.1016/j.maturitas.2011.02. 009.

52. Heaney RP. Pathophysiology of osteoporosis. Endocrinol Metab Clin N Am. 1998 Jun 1;27(2):255-65.

53. Gonnelli S, Caffarelli C, Tanzilli L, Alessi C, Tomai Pitinca MD, Rossi S, et al. The associations of body composition and fat distribution with bone mineral density in elderly italian men and women. J Clin Densitom. 2013;16(2):168-77 https://doi.org/10.1016/j.jocd.2012.02.013.

54. Reid IR. Fat and bone. Arch Biochem Biophys. 2010;503(1):20-7.

55. Hou J, He C, He W, Yang M, Luo X, Li C, et al. Obesity and bone health: a complex link. Front Cell Dev Biol. 2020;8(December):1-16.

56. Locquet $M$, Beaudart $C$, Reginster JY, Bruyère $O$, Locquet $M$, Beaudart $C$, et al. Association between the decline in muscle health and the decline in bone health in older individuals from the SarcoPhAge cohort. Calcif Tissue Int. 2018;104(3):273-84 https://doi.org/10.1007/s00223-018-0503-4.

57. Neto J, Ribeiro S. Concordância do diagnóstico de sarcopenia por diferentes propostas de avaliação, por BIA e DEXA. Rev Bras Nutr Esportiva. 2018;12(n. 74):776-85 http://www.rbne.com.br/index.php/rbne/article/ view/1134/815

58. Jang IY, Jung HW, Lee CK, Yu SS, Lee YS, Lee E, et al. Comparisons of predictive values of sarcopenia with different muscle mass indices in Korean rural older adults: a longitudinal analysis of the aging study of PyeongChang rural area. Clin Interv Aging. 2018;13:91-9.

59. Mazocco L, Chagas P. Associação entre o índice de massa corporal e osteoporose em mulheres da região noroeste do Rio Grande do Sul. Rev Bras Reumatol. 2017;57(4):299-305 https://doi.org/10.1016/j.rbr.2016.07. 009.

60. Głogowska-Szeląg J. Assessment of the relationship between bmd and body mass index bmi in women with postmenopausal osteoporosis. Wiad Lek. 2018;71(9):1714-8 https://pubmed.ncbi.nlm.nih.gov/30737 928/.

61. De Laet C, Kanis JA, Odén A, Johanson H, Johnell O, Delmas P, et al. Body mass index as a predictor of fracture risk: a meta-analysis. Osteoporos Int. 2005;16(11):1330-8.

62. Proietto J. Obesity and Bone. F1000Research. 2020;9:1-7.

63. Kim J, Lee S, Kim SS, Lee J-P, Kim JS, Jung JG, et al. Association between body mass index and fragility fracture in postmenopausal women: a cross-sectional study using Korean National Health and nutrition examination survey 2008-2009 (KNHANES IV). BMC Womens Health. 2021;21(1):1-9. https://doi.org/10.1186/s12905-021-01209-4.

\section{Publisher's Note}

Springer Nature remains neutral with regard to jurisdictional claims in published maps and institutional affiliations. 